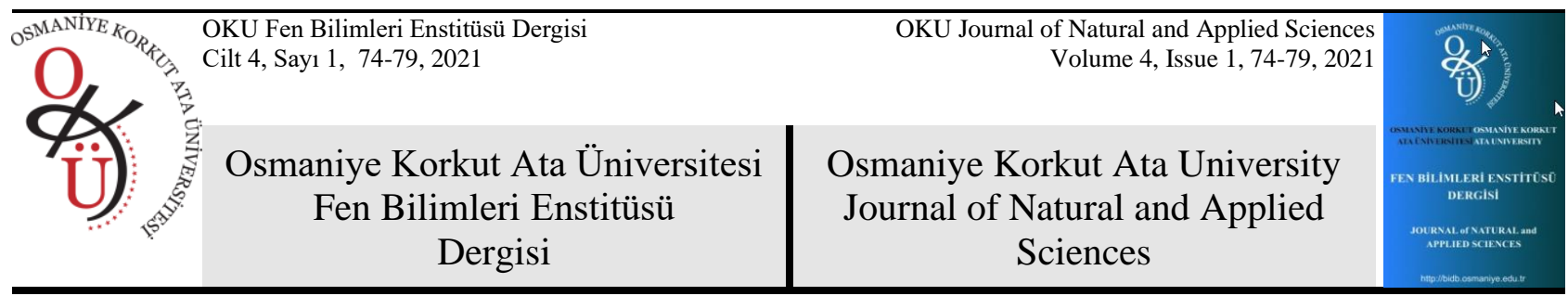

\title{
Armillaria mellea ve Tricholoma cedretorum Mantarlarının Farklı Dozlarının İlave Edildiği Topraklarda Karbon Mineralizasyonu
}

\author{
Selen Seyide YILMAZ ÇELİK ${ }^{1}$, Hüsniye AKA SAĞLIKER ${ }^{1}$, Nacide KIZILDAĞ ${ }^{2 *}$ \\ ${ }^{1}$ Osmaniye Korkut Ata Üniversitesi, Fen-Edebiyat Fakültesi, Biyoloji Bölümü, 8000, Osmaniye \\ ${ }^{2}$ Çukurova Üniversitesi, Merkezi Araştırma Laboratuvarı, 01330, Adana \\ ${ }^{1}$ https://orcid.org/ 0000-0002-7094-7502 \\ ${ }^{2}$ https://orcid.org/ 0000-0003-3807-1827 \\ ${ }^{3}$ https://orcid.org/ 0000-0001-6687-223X \\ *Sorumlu yazar: nkizildag@cu.edu.tr
}

\section{Araştırma Makalesi}

Makale Tarihçesi:

Gelis tarihi: 7 Kasım 2020

Kabul tarihi: 17 Aralık 2020

Online Yayınlanma: 2 Mart 2021

\section{Anahtar Kelimeler:}

Armillaria mellea

Tricholoma cedretorum

Karbon mineralizasyonu

Organik madde

\section{ÖZET}

Bu çalıșmada, Osmaniye ili- Hasanbeyli mevkiide bulunan Armillaria mellea (Physalacriaceae) ve Tricholoma cedretorum (Tricholomataceae) mantarlarının yetiştiği topraklar ile bu topraklara farklı oranlarda ilave edilen (toprak karbonuna eşdeğer $1 / 1 \mathrm{X}, 1 / 2 \mathrm{X}$ ve $1 / 4 \mathrm{X}$ oranda) mantarların toprak karbon mineralizasyonuna etkileri incelenmiştir. Bu amaçla, A. mellea ve T. cedretorum mantarları ile yetiştiği toprakların bazı fiziksel ve kimyasal özellikleri belirlenerek bu toprakların 42 günlük karbon mineralizasyonu $\mathrm{CO}_{2}$ respirasyonuna göre incelenmiştir. Topraklara ayrı ayrı karıştırılan toprak karbonuna eşdeğer $1 / 1 \mathrm{X}, 1 / 2 \mathrm{X}$ ve $1 / 4 \mathrm{X}$ oranında karbonlu mantar ilaveleri her iki toprakta mikroorganizma faaliyetini arttırmıştır. A. mellea mantarı karıştırılan toprakta daha yüksek karbon mineralizasyonu gözlenmiş olup $T$. cedretorum toprağ 1 ile arasında anlamlı fark bulunmamıştır $(\mathrm{P}>0,05)$. Bunun yanında her iki mantarın farklı dozlarının da $(1 / 1$ $\mathrm{X}, 1 / 2 \mathrm{X}$ ve $1 / 4 \mathrm{X})$ topraklara ilavesinde kendi aralarında anlamlı farklar yaratmadığı saptanmıştır. A. mellea mantarının kontrol toprağı ile yine farklı dozlarda A. mellea mantar ilavelerinin yapıldığı topraklarda daha yüksek karbon mineralizasyon oranı gözlenmiş olup, $T$. cedretorum uygulamaları arasında istatistiksel olarak anlamlı farklar bulunmuștur $(\mathrm{P}<0,05)$. Bu çalışma bulgularından elde edilen sonuçlara göre mikroorganizmaların mantar ilavelerini karbon kaynăg 1 olarak kullandıkları saptanmıştır.

\section{Carbon Mineralization in Soils with Different Doses of Armillaria mellea and Tricholoma cedretorum mushrooms}

\section{Research Article}

\section{Article History:}

Received: 7 November 2020

Accepted: 17 December 2020

Published online: 2 March 2021

\section{Keywords:}

Armillaria mellea

Tricholoma cedretorum

Carbon mineralization

Organic matter

\begin{abstract}
In this study, the soils where Armillaria mellea (Physalacriaceae) and Tricholoma cedretorum (Tricholomataceae) mushrooms grow in the Osmaniye-Hasanbeyli region and the effects of mushrooms added to these soils at different rates (1/1X, $1 / 2 \mathrm{X}$ and $1 / 4 \mathrm{X}$ ratio equivalent to soil carbon) on soil carbon mineralization were investigated. For this purpose, some physical and chemical properties of A. mellea and $T$. cedretorum mushrooms and the soils where they grow were determined and 42-day carbon mineralization of these soils was examined by $\mathrm{CO}_{2}$ respiration. Addition of equal (1/1X), half (1/2X) and quarter (1/4X) amounts of soil carbon containing mushrooms to both soils separately increased microorganism activity. Higher carbon mineralization was observed in the soil mixed with A. mellea mushroom and no significant difference was found between $T$. cedretorum soil $(\mathrm{P}>0,05)$. In addition, it was found that the addition of different doses $(1 / 1 \mathrm{X}, 1 / 2 \mathrm{X}$ and $1 / 4 \mathrm{X}$ ) of both mushrooms to the soil did not make a significant difference between them. A higher carbon mineralization rate was observed in control soil of A. mellea mushroom and soils where A. mellea mushroom was added in different
\end{abstract}


doses and statistically significant differences were found between T. cedretorum applications $(\mathrm{P}<0,05)$. Based on the results obtained from the findings of this study, it was determined that microorganisms use mushrooms as a carbon source.

To Cite: Çelik SSY., Sağlıker HA., Kızıldağ N. Armillaria mellea ve Tricholoma cedretorum Mantarlarının Farklı Dozlarının İlave Edildiği Topraklarda Karbon Mineralizasyonu. Osmaniye Korkut Ata Üniversitesi Fen Bilimleri Enstitüsü Dergisi 2021; 4(1): 74-79.

\section{Giriş}

Toprak organik maddesinin (TOM) korunmas1, ayrışması ve topraklara karıştırılan ilave dengesi sürdürülebilir toprak yönetiminde önemli bir yere sahiptir [1]. Yeşil gübreleme, ahır gübresi, kompost ve biyokömür gibi uygulamalar topraklarda var olan organik maddenin arttırılmasına yönelik çalışmalardır. $\mathrm{Bu}$ uygulamaların bir kısmı toprağa doğrudan besin elementi katkısı sağlarken, bir kısmı da toprakların fiziksel, kimyasal ve biyolojik özelliklerini iyileştirici etkide bulunmaktadır [2,3]. Toprağa ilave edilen organik madde kaynaklarının kalitesi, uygulama ile doz miktarları ve ayrışma dereceleri topraktaki organik maddeyi arttırmak amaciyla son derece önemli bir yer tutmaktadır.

TOM bileşenlerinden biri olarak toprakta indüklenen karbonun toplamı olarak bilinen toprak organik karbonu (TOK), toprak yaşamının en temel ölçütüdür. Temel olarak TOK, bitki ve hayvan kalıntıları, ölü ve yaşayan mikroorganizmalar, kök sızıntıları ve toprak biyotasının çözülmesi ve çürümesiyle toprağa girmektedir [4].

Hem aerobik hem de anaerobik koşullarda mikroorganizmalar aracılığı ile topraktan $\mathrm{CO}_{2}$ çıkışı olarak bilinen toprak karbon mineralizasyonu [5]; ekosistem verimliliği, sürdürülebilirliği ve uzun vadeli karbon sekestrasyonunda önemli rol oynamaktadır [6,7]. Topraktan atmosfere salınan $\mathrm{CO}_{2}$ miktarı, toprağa ilave edilen organik maddelerin kalitesi, kantitesi ve $\mathrm{C} / \mathrm{N}$ oranından oldukça fazla etkilenmektedir [8,9]. Bitkisel karbon kaynağı ilaveleri TOM ayrışma hızını değiştirebilmektedir [10]. Yüksek $\mathrm{C} / \mathrm{N}$ oranı içeren organik materyallerin ayrışması için toprakta yaşayan mikroorganizmalar, ayrışma için daha uzun süreye ihtiyaç duymaktadır [11].

$\mathrm{Bu}$ çalışmanın amacı, Osmaniye ili- Hasanbeyli mevkiide bulunan Armillaria mellea (Physalacriaceae) ve Tricholoma cedretorum (Tricholomataceae) mantarlarının yetiştiği topraklar ile bu topraklara farklı oranlarda ilave edilen (toprak karbonuna eşdeğer 1/1X, 1/2X ve
1/4X) mantarların toprak karbon mineralizasyonuna etkilerini belirlemektir.

\section{Materyal ve Metot}

$\mathrm{Bu}$ çalışma için, Doğu Akdeniz Bölgesinde Osmaniye ili-Hasanbeyli mevkisi örneklik alan olarak seçilmiştir. Osmaniye'de, Akdeniz iklim koşulları hakim olup yazları sıcak ve kurak, kışlar 1lık ve yağışlıdır. Ortalama ve en yüksek sicaklıklar sırasıyla $18,2{ }^{\circ} \mathrm{C}$ ve $42,8^{\circ} \mathrm{C}$ iken, yağ 1 ş süresi kış ve sonbahar aylarında diğer aylardan daha fazla olup yıllık ortalama yağış miktarı 767,6 mm'dir [12].

Osmaniye-Hasanbeyli mevkiiden toplanan Armillaria mellea (Physalacriaceae) ve Tricholoma cedretorum (Tricholomataceae) mantarları ile bu mantarların yetiştiği $0-10 \mathrm{~cm}$ derinliğindeki toprakları araştırma materyalini oluşturmaktadır. Topraklar laboratuvarda kurutulup 2 mm'lik elekle elenmiş, mantarlar ise doğada örneklendikten sonra laboratuvara getirilip $70^{\circ} \mathrm{C}$ 'de kurutularak analizlere hazır hale getirilmiştir. Toprakların bünye tipi hidrometre yöntemi ile [13], toprak pH's1 1:2,5'lik toprak su karışımında pH metre (InoLab) ile [14], kireç içeriği (\%) kalsimetre (Scheibler) ile [15], tarla kapasitesi (TK, \%) 1/3 atmosferlik basınçlı vakum pompası ile belirlenmiştir [16]. Toprakların ve mantarların $\mathrm{C}$ içeriği $(\% \mathrm{C})$ Anne metodu [17], toplam $\mathrm{N}$ içeriği ise $(\% \mathrm{~N})$ Kjeldahl metoduna göre yapılmıştır.

Armillaria mellea ve Tricholoma cedretorum mantarlarının yetiştiği topraklar ile toprak karbonuna göre farkl1 oranlarda $(1 / 1 \mathrm{X}, 1 / 2 \mathrm{X}$ ve 1/4X) Armillaria ve Tricholoma mantarlarının karıştırıldığı toprakların karbon mineralizasyonu $\mathrm{CO}_{2}$ respirasyonu yöntemine göre kontrollü koşullar altında $28^{\circ} \mathrm{C}$ de 42 gün boyunca incelenmiştir [18].

Farklı oranlarda Armillaria ve Tricholoma mantarları karıştırılan topraklar 750 mL'lik inkübasyon kavanozlarına aktarıldıktan sonra tarla kapasitelerinin \%80'ine kadar nemlendirilmiştir. İçinde $40 \mathrm{~mL} \mathrm{Ba}(\mathrm{OH})_{2}$ bulunan beher inkübasyon kavanozuna yerleştirildikten sonra kavanozun kapağı kapatılarak $28^{\circ} \mathrm{C}$ 'ye ayarlanmış inkübatöre 
yerleştirilmiştir. Mikrobiyal oksidasyon sonucu ortaya çıkan $\mathrm{CO}_{2}$ gazı karbonu, $100 \mathrm{~g}$ kuru toprakta $\mathrm{mg}$ olarak ifade edilmiştir $[\mathrm{mg}$ $\mathrm{C}\left(\mathrm{CO}_{2}\right) / 100 \mathrm{~g}$ kuru toprak]. Herhangi bir mantar ilavesinin yapılmadığı topraklar, kontrol toprakları olarak ifade edilmiştir. Karbon mineralizasyon oranları 42 günlük inkübasyon periyodunda üretilmiş kümülatif $\mathrm{C}\left(\mathrm{CO}_{2}\right)$ değerlerinin toplam organik karbona bölünmesi ile hesaplanmıştır.

Araştırma verilerinin istatistiksel analizi SPSS paket programı ile yapılmıştır. İki farklı mantarın ve topraklarının bazı fiziksel ve kimyasal özellikleri ile karbon mineralizasyonları arasındaki kıyaslamalarda Varyans analizi (One Way Anova) ve Tukey HSD testi kullanılmıştır [19]. Elde edilen üç tekrarlı veriler çizelge ve şekillerde ortalama \pm standart hata şeklinde ifade edilmiştir. Karşılaştırmalarda önem düzeyi $\mathrm{P}<0,05$ olarak alınmıştır.

\section{Bulgular ve Tartışma}

Armillaria mellea ile Tricholoma cedretorum mantarları ve bu mantarların yetiştiği toprakların bazı kimyasal analiz sonuçları istatistiksel olarak değerlendirilmiş, ortalama ve standart hata değerleri hesaplanmış, Tablo 1' de verilmiştir.

Her iki mantarın yetiştiği topraklar kumlu killi bulunmuştur. Kum, kil ve silt içerikleri açısından topraklar arasında anlamlı fark gözlenmemiştir. Toprakların tarla kapasiteleri (\%) arasinda istatistiksel olarak $\mathrm{P}<0,05$ düzeyinde anlamlı bir fark gözlenmiştir. Her iki toprak hafif bazik olup pH'ları arasında anlamlı fark saptanmamıştır $(\mathrm{P}>0,05)$. Armillaria $(\% 3,65)$ ve Tricholoma $(\% 6,45)$ topraklarının karbon içerikleri açısından, varyans analizi sonucunda anlamlı fark bulunmuştur $(\mathrm{P}=0,023)$. Aynı şekilde her iki toprağın azot içerikleri değerlendirildiğinde aralarında istatistiksel olarak anlamlı fark olduğu gözlenmiştir $(\mathrm{P}<0,001)$. En yüksek $\mathrm{C} / \mathrm{N}$ oranı, Armillaria mantarının yetiştiği toprakta saptanmış olup Tricholoma mantarının yetiştiği toprak ile arasında anlamlı fark bulunmuştur $(\mathrm{P}<0,05)$. Toprakların $\mathrm{K}$ ve $\mathrm{Mg}$ içerikleri değerlendirildiğinde; en yüksek $\mathrm{K}$ ve $\mathrm{Mg}$, yine Armillaria mantarının yetiştiği toprakta bulunmuş olup Tricholoma toprağ olarak fark gözlenmemiştir. Mantarların karbon ve azot içerikleri en yüksek Armillaria mantarında belirlenmiş olup Tricholoma mantarı ile aralarında fark saptanmamıştır (Tablo 1).
Tablo 1. Armillaria mellea ve Tricholoma cedretorum mantarlarının ve topraklarının bazı kimyasal analizleri $(n=3)$

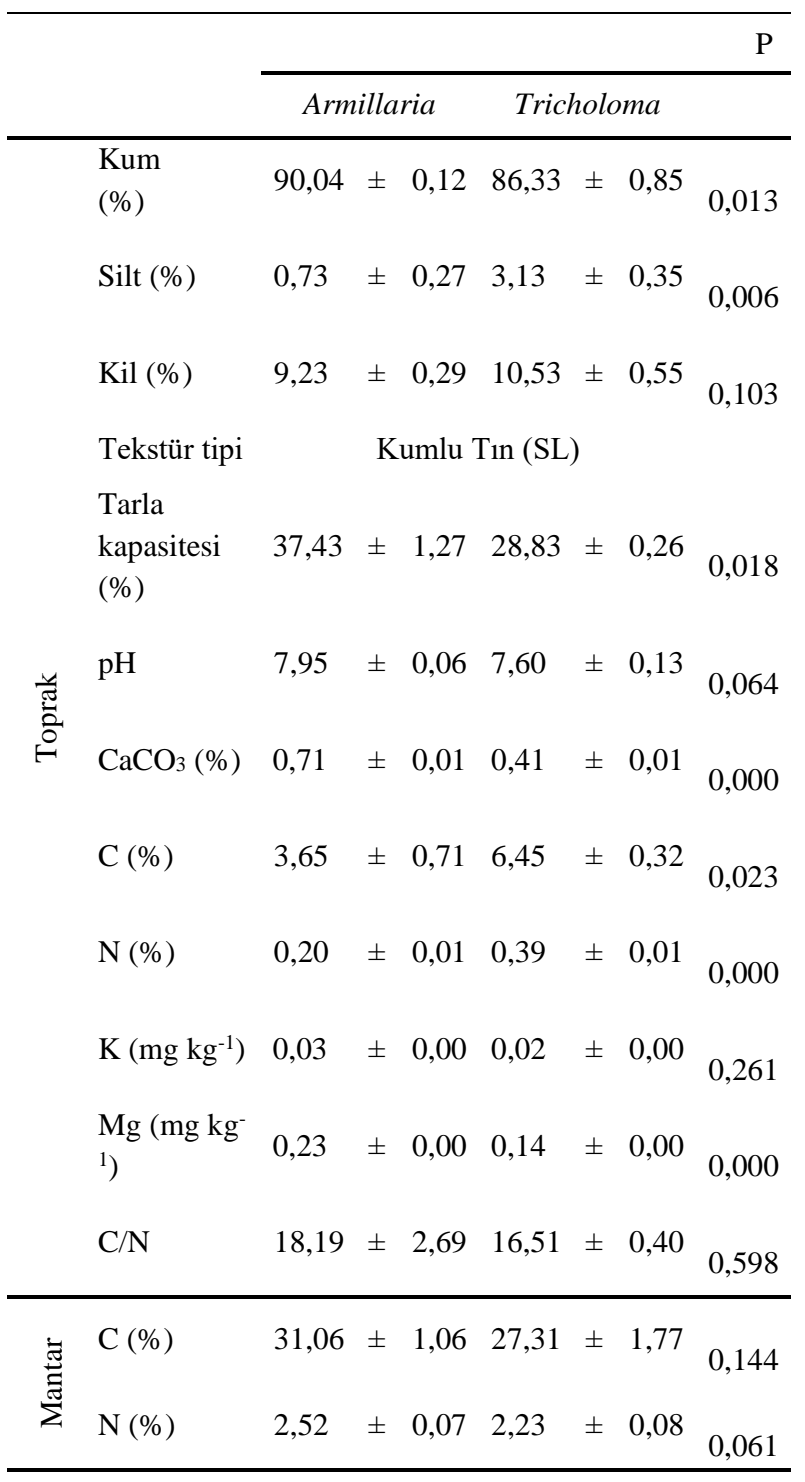

Kumulatif karbon mineralizasyonu $[\mathrm{mg}$ $\mathrm{C}\left(\mathrm{CO}_{2}\right) / 100 \mathrm{~g}$ kuru toprak] Armillaria mantarının $1 / 1 \mathrm{X}$ uygulamasında en yüksek iken $(53,63 \mathrm{mg}$ C), 1/4X uygulamasında en düşük $(48,98 \mathrm{mg} \mathrm{C})$ bulunmuştur (Şekil 1). 


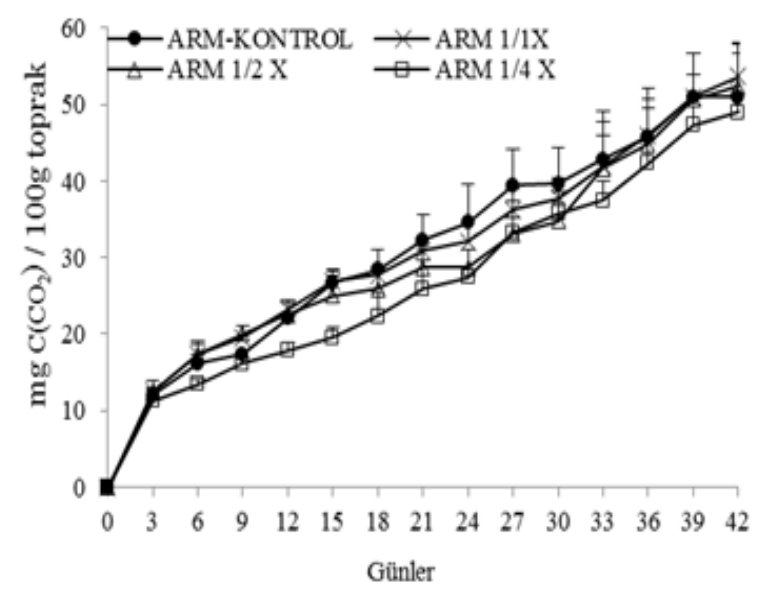

Şekil 1. Armillaria mellea mantarlarının yetiştiği toprakların 42 günlük kümülatif karbon mineralizasyonu [mg $\mathrm{C}\left(\mathrm{CO}_{2}\right) / 100 \mathrm{~g}$ Toprak] $(n=3$, ortalama \pm standart hata)

Buna karşın Tricholoma mantarının uygulamaları kendi içinde değerlendirildiğinde en yüksek 1/4X oranında mantar karıştırılan uygulamada $(51,85$ mg C) iken, en düşük Tricholoma' nın kontrol toprağında (41,27 mg C) gerçekleşmiştir (Şekil 2). Armillaria mantarının yetiştiği kontrol toprağında 50,94 mg iken, Tricholoma'nın yetiştiği kontrol toprağında ise $41,27 \mathrm{mg}$ olmuş ve iki mantar toprağı arasında anlamlı fark bulunmamıştır $(\mathrm{P}>0,05)$. Bunun yanında her iki mantarın farklı dozlarının (1/1X, 1/2X ve 1/4X) topraklara ilavesinde de kendi aralarında anlamlı farklar olmadığ 1 saptanmıştır. Her iki mantarın tüm uygulamaları değerlendirildiğinde hem kontrol hem de doz ilavelerinde ilk 3 günde kolay ayrışabilen organik maddelerin, mikroorganizmalar tarafından hızlı bir şekilde tüketildiği gözlenmiştir.

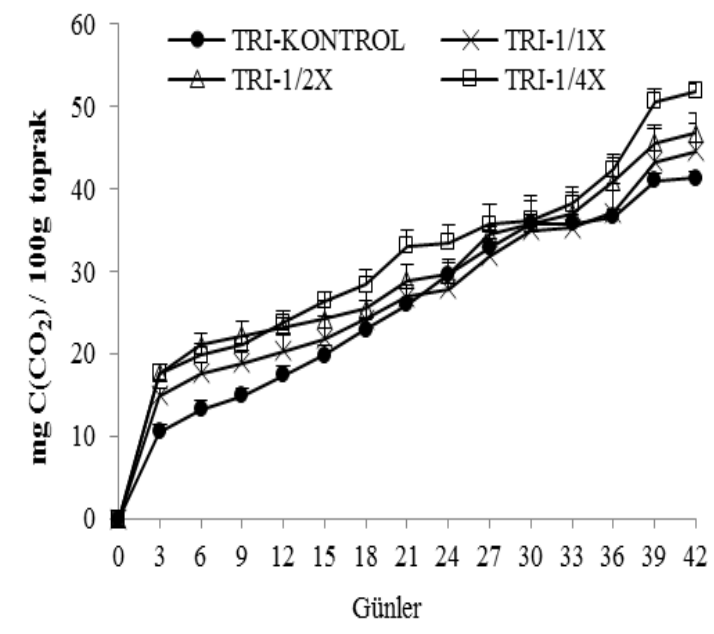

Şekil 2. Tricholoma cedretorum mantarlarının yetiştiği toprakların 42 günlük kümülatif karbon mineralizasyonu [mg $\mathrm{C}\left(\mathrm{CO}_{2}\right) / 100 \mathrm{~g}$ Toprak] $(n=3$, ortalama \pm standart hata)
Karbon mineralizasyon oranları, en yüksek Armillaria mantarının yetiştiği kontrol toprağ yine farklı dozlarda Armillaria mantar ilavelerinin yapıldığ1 topraklarda gerçekleşmiştir (Şekil 3). Tüm uygulamalar incelendiğinde, en yüksek karbon mineralizasyon oran 1 1/1X Armillaria mantarı karıştırılmış toprakta olurken en düşük ise Tricholoma mantarının yetiştiği kontrol topraklarında gerçekleşmiş olup aralarında anlamlı fark bulunmuştur $(\mathrm{P}<0,05)$. Armillaria mantarı karıştırılmış topraklarda doz arttıkça karbon mineralizasyon oranları azalmış buna karşın Tricholoma mantarı karıştırılan topraklarda ise tam tersi bir durum meydana gelmiştir. Her iki mantarın artan dozları kendi içlerinde (1/1X, 1/2X ve $1 / 4 \mathrm{X}$ ) değerlendirildiğinde istatistiksel anlamda aralarında anlamlı fark gözlenmemiştir.

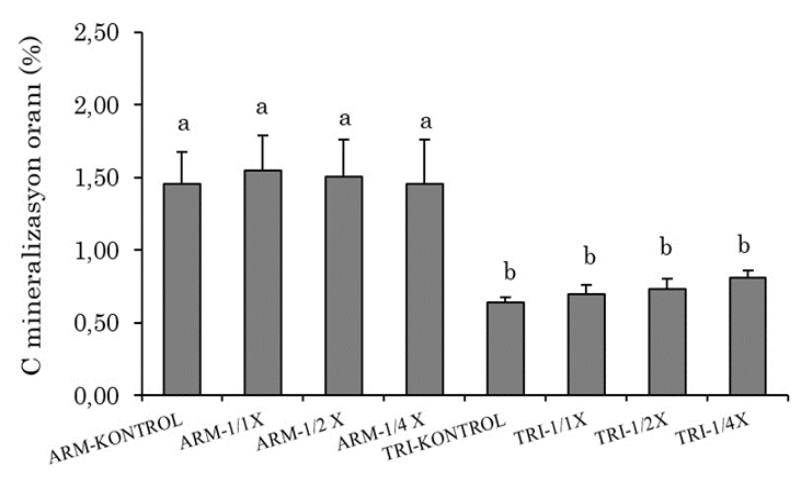

Şekil 3. Armillaria mellea ve Tricholoma cedretorum mantarlarının yetiştiği toprakların 42 günlük karbon mineralizasyon oranları $(\%, n=3$, ortalama \pm standart hata)

Armillaria mantarının yetiştiği toprağın $\mathrm{C} / \mathrm{N}$ oranı $(18,19)$, Tricholoma mantarının yetiştiği topraklardan $(16,51)$ daha yüksek bulunmuştur. Kızıldağ ve ark. [3], organik maddenin miktarı, kalitesi, dışarıdan ilave edilen organik kaynağın $\mathrm{C} / \mathrm{N}$ oranının toprak organik madde mineralizasyonunda önemli bir rol oynadığını rapor etmişlerdir. $\mathrm{Bu}$ çalışmada, Armillaria topraklarında tüm uygulamalarda 42 günlük karbon mineralizasyonu, Tricholoma topraklarından daha yüksek olmuştur. $\mathrm{Bu}$ durum Armillaria mantarının yetiştiği toprakların ve ilave edilen mantarın $\mathrm{C} / \mathrm{N}$ oranı ile açıklanabilir. Mantarların ekolojik ve ekonomik anlamda önemli bir role sahip oldukları bilinmektedir [20,21]. Karasal ekosistemlerde mikro mantarlar, organik maddeyi ayrıştırarak karbon ve azot döngüsünde çok büyük rol oynamaktadırlar [22]. Buna karşın literatürde, makro mantarların iklim ve besin elementi içerikleri gibi abiyotik faktörleri çalışılmış olmasına rağmen, biyotik etkileşimler özellikle de mikrobiyal etkileşimleri ile ilgili 
çalışmalar oldukça sınırlıdır [23]. Bunun yanında mikrobiyal etkileşimlerin bir göstergesi olarak bilinen toprak karbon mineralizasyonuna mantarların olası etkileri ile ilgili herhangi bir çalışmaya rastlanmamıştır. $\mathrm{Bu}$ bağlamda bu çalışma ilk kez yapılması bakımından özgün bir değere sahiptir. Bu çalışmada, farklı dozlarda Armillaria mantarı topraklara karıştırıldığında mikroorganizma faaliyetinin mantar ilavesi olmayan kontrol topraklarına göre daha düşük çıktığı gözlenmiştir.

Seskiterpen aril esterler, Armillaria mantar cinsinin sekonder metobolitlerinin ana grubunu oluşturmaktadır [24]. Bu ester gruplarından Melleolide-K, Melleolide-L ve Melleolide-M esterlerinin ise antibakteriyel ve antifungal etki gösterdiği bilinmektedir [25]. Mikroorganizma faaliyetindeki mantar ilaveli düşüşün nedeninin Armillaria mantarının yapisında bulunan bazı sekonder metobolitlerden kaynaklanabileceği düşünülmektedir. Mikroorganizma çeşitliliği, kommunite yapısı ve etkinliğinin topraktaki mikroorganizma faaliyetini etkilediği bilinmektedir. Oh ve ark. [23], Tricholoma matsutake mantarının toprak mikroorganizmaları üzerinde dominant bir etkiye sahip olduğunu rapor etmişlerdir.

\section{Sonuç ve Öneriler}

$\mathrm{Bu}$ çalışmada Armillaria mellea ve Tricholoma cedretorum mantarlarının yetiştiği kontrol topraklar ile toprak karbonuna göre hesaplanan farklı oranlarda (1/1X, 1/2X ve 1/4X) Armillaria ve Tricholoma mantarlarının karıştırıldığ 1 toprakların karbon mineralizasyonu kontrollü koşullar altında $28^{\circ} \mathrm{C}$ de 42 gün boyunca incelenmiştir.

Kümulatif karbon mineralizasyonu Armillaria toprağında, Tricholoma toprağına göre daha yüksek bulunmuştur. En yüksek karbon mineralizasyon oranları, Armillaria mantarının yetiştiği kontrol toprağı ile yine farklı dozlarda Armillaria mantar ilavelerinin yapıldığ topraklarda gerçekleşmiştir. Armillaria mantarı karıştırılmış topraklarda doz arttıkça karbon mineralizasyon oranları azalmış buna karşın Tricholoma mantarı karıştırılan topraklarda ise tam tersi bir durum meydana gelmiştir. $\mathrm{Bu}$ çalışmadan yola çıkarak ekonomik öneme sahip mantarların üretilmesi, kimyasal kompozisyonlarının (aminoasit içerikleri) belirlenmesi ve üretim sonucunda ortaya çıkan verimli mantar kompostlarının, topraklara karıştırılıp yeniden değerlendirilmesi önerilmektedir.

\section{Çıkar Çatışması Beyanı}

Makale yazarları aralarında herhangi bir çıkar çatışması olmadığını beyan ederler.

\section{Araştırmacıların Katkı Oranı Beyan Özeti}

Yazarlar makaleye eşit oranda katkı sağlamış oldukların beyan ederler.

\section{Teşekkür}

$\mathrm{Bu}$ çalışmanın yapılmasına olanak sağlayan Osmaniye Korkut Ata Üniversitesine teşekkür ederiz.

\section{Kaynakça}

[1] Dostal J. Results of the long-term organic matter balance investigations in Usti Nad Orlici district and the trends in the whole Czech Republic, Agronomy and Soil Science 2002; 48: 155-160.

[2] Cabrera ML., Dkisseland A., Vigil MF. Nitrogen mineralization from organic materials: research opportunities, Journal of Environmental Quality 2005; 34: 75-79

[3] Kızıldăg N., Aka Sağlıker H., Darıcı C. Comparison of the effects of Tannin and Azadirachtin on carbon mineralization in soils of Quercus coccifera from Eastern Mediterranean Region, Ekoloji 2012; 21: 47-53.

[4] Khatoon H., Solanki P., Narayan M., Tewari L., Rai JPN. Role of microbes in organic carbon decomposition and maintenance of soil ecosystem, International Journal of Chemical Studies 2017; 5(6): 1648-1656.

[5] Raich JW., Potter CS. Global patterns of carbon-dioxide emissions from soils. Global Biogeochemistry Cycles 1995; 9: 23-36.

[6] Lal R. Soil carbon sequestration to mitigate climate change, Geoderma 2004; 123: 1-22. doi:10.1016/j.geoderma.2004.01.032

[7] Luo Y, Zhou X. Soil respiration and the environment. Academic Press. 2006; 328 pp.

[8] Agehara S., Warncke DD. Soil alternate wetting and drying pure and temperature effects on nitrogen release from organic nitrogen sources, Soil Science Society of America Journal 2005; 69: 1844-1855.

[9] Hossain MB., Rahman MM., Biswas JC. Carbon mineralization and carbon dioxide 
emission from organic matter added soil under different temperature regimes, International Journal of Recycling Organic Waste in Agriculture 2017; 6: 311-319.

[10] Aka Sağlıker H., Kızıldağ N., Çiçek B. Evaluation of carbon mineralisation in soils added thyme leaves and mospilan at different dosages, Journal of Environmental Protection and Ecology 2017; 18: 862-870.

[11] Brady NC., Weil RR. The nature and properties of soils. ISBN: 978-0-13-227938-3. Pearson Prentice Hal Inc., New Jersey USA., 2008; 1-965

[12] Yüce MI., Aksoy H., Önöz B., Çetin M., Eriş M., Burgan Hİ., Oğuz A., Kalaçi O. İklim değişikliğinin yağışlar üzerine etkisi: Kahramanmaraş ve Osmaniye örneği. 10. Ulusal Hidroloji Kongresi. 9-12 Ekim, 2019, Muğla Sitk1 Koçman Üniversitesi, Bildiriler Kitab1, 2019; 375-388.

[13] Bouyoucos GS. A recalibration of the hydrometer for making mechanical analysis of soil, Agronomy Journal 1951; 43: 434-438.

[14] Jackson ML. Soil chemical analysis. (Upper Saddle River Prentice Hall: NJ, USA) 1958.

[15] Allison LE., Moodie CD. Carbonate, American Society of Agronomy, 1965; 9-15.

[16] Demiralay I. Toprak fiziksel analizleri, Atatürk Üniversitesi Ziraat Fakültesi, Erzurum, 1993.

[17] Duchaufour P. Precis de Pedologie. 3 ed. Masson, Paris, 1970; 481 p.

[18] Schaefer R. Characteres et evolution des activites microbiennes dans une chaine de sols hidromorphes mesotrophiques de la plaine d'Alsace, Revue d'écologie et de biologie du sol 1967; 4: 567-592.

[19] Kleinbaum DG., Kupper LL., Muller KE., Nizam A. Applied regression analysis and other multivariable methods, Duxbury Press, Pacific Grove, CA, USA. 1998.

[20] Han X., Hu H., Shi X., Zhang L., He J. Effects of different agricultural wastes on the dissipation of PAHs and the PAH-degrading genes in a PAH-contaminated soil, Chemosphere 2017; 172: 286-293.
[21] Lou Z., Sun Y., Bian S., Ali Baig S., Hu B., $\mathrm{Xu} \mathrm{X}$. Nutrient conservation during spent mushroom compost application using spent mushroom substrate derived biochar, Chemosphere 2017; 169: 23-31.

[22] Rayner ADM., Boddy L. Fungal decomposition of wood. Its biology and ecology, Chichester, Sussex, UK: John Wiley and Sons Ltd. 1988.

[23] Oh SY., Fong JJ., Park MS., Lim YW. Distinctive feature of microbial communities and bacterial functional profiles in Tricholoma matsutake dominant soil, PloS One, 2016; 11: e0168573.

[24] Donnelly D., Sanada S., O’Reilly J., Polonsky J., Prange T., Pascard C. Isolation and structure (X-ray analysis) of the orsellinate of armillol, a new antibacterial metabolite from Armillaria mellea, Journal of the Chemical Society, Chemical Communications 1982; 2: 135137.

[25] Momose I., Sekizawa R., Hosokawa N., Iinuma H., Matsui S., Nakamura H., Naganawa H., Hamada M., Takeuchi T. Melleolides K, L and M, new melleolides from Armillaria mellea, The Journal of Antibiotics 2000; 53: 137-143. 